\title{
Pharmacokinetics of paracetamol after cardiac
} surgery

\author{
C S Hopkins, S Underhill, P D Booker
}

\begin{abstract}
Plasma concentration was measured after rectal and nasogastric administration of paracetamol $15 \mathrm{mg} / \mathrm{kg}$ to 28 febrile children aged between 9 days to 7 years who had undergone cardiac surgery. After equivalent doses, rectal administration in neonates and children on the first postoperative day was found to produce plasma concentrations below the therapeutic range with higher concentrations after nasogastric paracetamol on the second postoperative day. There was less variance in plasma paracetamol concentrations in neonates. Both plasma elimination half life and area under the plasma concentration time curve were significantly increased in neonates after suppository dosing compared with older children. There was no difference in antipyretic effect between the two routes of administration, but this was much lower than that previously reported in febrile children.
\end{abstract}

Awareness of the possible role of aspirin in the aetiology of Reye's syndrome and its subsequent withdrawal from everyday paediatric practice has led to an increasing reliance upon paracetamol as the simple analgesic and antipyretic of choice in children. In some situations oral treatment may be inappropriate and rectal administration by suppository has been shown to be an effective and practical alternative. ${ }^{12}$ Situations in which the rectal route may be chosen include those patients whose clinical condition precludes oral treatment, for example, children who have recently undergone major surgery.

The administration of paracetamol may be necessary in the postoperative period for either its analgesic or antipyretic effects or both. Much recent interest has centred upon safe and efficient forms of postoperative analgesia in neonates, and paracetamol may have a role after some forms of surgery. ${ }^{3}$

An abnormally high body temperature is commonly found during the first 24-48 hours after cardiac surgery. The cause for this is unknown but harm to the patient may be expected to become more likely with increasing temperature as a result of increasing myocardial oxygen demand. At temperatures above $41^{\circ} \mathrm{C}$ severe and permanent damage to the central nervous system can occur. A recommended scheme of management for postoperative fever in paediatric cardiac surgical patients is paracetamol suppositories every four hours in a dose of $10 \mathrm{mg} / \mathrm{kg}$ when rectal temperature exceeds $38 \cdot 3^{\circ} \mathrm{C}^{4}$
Little is known about the pharmacokinetics of paracetamol in young children, particularly in those who are severely ill. Pharmacokinetic studies in healthy adults show plasma elimination half life $\left(t^{1 / 2} \beta\right)$ to be 2.5 hours after oral and intravenous administration with a reduced bioavailability after oral dosing, possibly due to 'first-pass' metabolism. ${ }^{5}$ The bioavailability of the rectal preparation is approximately $80 \%$ of that of the oral formulation. ${ }^{6}$

Investigations in neonates have thus far been limited to urinary excretion studies in small numbers of healthy patients. Various authors report differing values, finding $t^{1 / 2} \beta$ to be prolonged in neonates at 3:5 hours compared with $1 \cdot 9-2 \cdot 2$ hours in children and adults ${ }^{7}$ or with no significant difference between mean $t^{1 / 2}$ $\beta$ in neonates (4.9 hours), children (4.5 hours), and adults (3.6 hours). ${ }^{8}$ Data from two cases of maternal paracetamol overdose in which delivery took place soon after have shown gross prolongation of $t^{1 / 2} \beta$ in neonates of 10 hours and 26 hours. ${ }^{9} 10$

Estimates of $t^{1 / 2} \beta$ based upon measurement of plasma concentrations after oral administration in children range from a mean of $2 \cdot 15$ hours ${ }^{11}$ to $2 \cdot 3$ hours. ${ }^{12}$ It has also been shown that accumulation of paracetamol may occur when doses are repeated in infants and children at regular intervals for more than 24 hours. ${ }^{12}$ Despite the comparatively low level of activity of the cytochrome $P-450$ system in small infants cases of paracetamol toxicity have been described. Neonates are capable of forming the reactive intermediate that causes hepatocellular damage. ${ }^{13} 14$

We are unaware of any previous studies comparing plasma concentrations in children dosed by the oral and rectal routes after major surgery. This study was therefore designed to investigate the plasma concentrations of paracetamol achieved by rectal and nasogastric doses given to children after major cardiovascular surgery, and to see whether any age dependent differences in pharmacokinetic parameters exist under these circumstances.

Patients and methods

Twenty eight patients who had undergone cardiac surgery took part in the study. The protocol was approved by the ethical review committee of the Royal Liverpool Children's Hospital and informed parental consent was obtained. The children were divided into three groups by age: neonates (up to 1 month), infants ( 1 month to 1 year) and children (1 to 7 years). Patients were excluded if they had

\author{
Dr C S Hopkins, \\ Leighton Hospital, Leighton, \\ Accepted 27 March 1990 \\ Anaesthesia, \\ Children's Hospital \\ C S Hopkins \\ $S$ Underhill \\ P D Booker
}


received paracetamol within the previous 16 hours or if their plasma bilirubin concentration was raised at the time of the study.

Most patients were in the early postoperative stages of cardiac surgery and at the time of the study were in a state of cardiovascular stability and were being artificially ventilated in the intensive care unit. They were all receiving a number of drugs including morphine, midazolam, vecuronium bromide, antibiotics, inotropes, and vasodilators. The infants and children had undergone a variety of procedures using cardiopulmonary bypass, but owing to the comparatively small number of neonates for open heart surgery, we included five patients who had closed cardiac procedures. These patients, however, were sick enough to require invasive cardiovascular monitoring.

A dose of paracetamol was given rectally on the first postoperative day if the rectal temperature was greater than $38 \cdot 3^{\circ} \mathrm{C}$, the dose used being as close to $15 \mathrm{mg} / \mathrm{kg}$ as the available strengths of suppository would allow. Before its administration a $0.5 \mathrm{ml}$ blood sample was taken from the arterial line and subsequently at 30 , $60,90,120$ minutes, 3, 4, 5, 6, and 8 hours. Evidence of expulsion of the suppository was sought throughout the study period. McCarthy's paracetamol suppositories were used. These are made up in a triglyceride base and are available in strengths of 125 and $250 \mathrm{mg}$ (OS-IL, Suppocir Ltd). The $62.5 \mathrm{mg}$ suppositories were made up in the hospital pharmacy by accurately dividing a $125 \mathrm{mg}$ suppository by weight.

On the second postoperative day, providing bowel sounds were present, the process was repeated with paracetamol via a nasogastric tube. The dose used was $15 \mathrm{mg} / \mathrm{kg}$ given to the nearest $12 \mathrm{mg}$ (that is, $0.5 \mathrm{ml}$ of Calpol (Calmic) infant suspension $120 \mathrm{mg}$ in $5 \mathrm{ml}$ ). After collection the samples were centrifuged and the separated plasma stored at $-20^{\circ} \mathrm{C}$ until assayed for paracetamol. The assay used was the Acetaminophen TDx assay. This is a commercially available fluorescence polarisation immunoassay (Abbott Pharmaceuticals) whose accuracy has been shown over a wide range of concentrations when compared with high pressure liquid chromatography (Abbott Laboratories, data on file). When assaying standard preparations over the range of plasma concentrations encountered, the coefficient of variability of this method in our hands was $<5 \%$. Known sources of error with this assay include the presence of unconjugated bilirubin, coumarin anticoagulants, and abnormal concentrations of haemoglobin, lipids, and total proteins, none of which were present in our patients. Assay specificity, allowing for concurrent administration of other drugs, was inferred from the zero results obtained in all cases before administration of paracetamol by either route.

During the study period rectal temperature was continuously monitored with a thermistor probe and temperature recorded at the time of each blood sample.

Pharmacokinetic parameters were calculated from standard formulae. The area under the plasma concentration time curve (AUC) was determined by the linear trapezoidal rule for data points up to 480 minutes, and $t^{1 / 2} \beta$ from the slope of the least squares regression line calculated for data points between 180-480 minutes on a semilog plot of individual plasma concentration against time, assuming an open two compartmental pharmacokinetic model for paracetamol:

$$
\beta=2 \cdot 303 \times \text { slope, and } t^{1} / 2 \beta=0 \cdot 693 / \beta \text {. }
$$

The maximum plasma paracetamol concentration for each patient was noted (Cmax) as was the time at which each peak occurred (Tmax). The values for AUC and Cmax were normalised for dose before subjecting them to within age group comparison using the Kruskal-Wallis one way analysis of variance and to intergroup comparison using analysis of variance. Interaction between dose, AUC, and Cmax and the effects of dose, AUC, and Cmax on the observed maximum individual fall in temperature, were analysed using linear regression.

\section{Results}

Twenty eight children were studied, and all received a rectal dose of paracetamol on the first postoperative day. It was possible to restudy 13 patients 24 hours later after a nasogastric dose of paracetamol. Because of technical reasons temperature data were only collected from five of the neonates after suppository administration. Retention of suppository occurred in every subject.

Demographic data and details of doses are given in table 1 . Only two of the 28 rectally dosed patients achieved normalised plasma concentrations within the $10-20 \mu \mathrm{g} / \mathrm{ml}$ range. In contrast seven of the 13 nasogastrically dosed patients achieved plasma concentrations in this range.

Figures 1 to 6 show individual plasma concentration against time for the three age groups. Summary statistics derived from these are given in table 2. There was no significant difference in AUC between suppository and nasogastric

Table 1 Demographic and dose data for all groups. Figures are mean (95\% confidence interval)

\begin{tabular}{|c|c|c|c|c|c|}
\hline & $\begin{array}{l}\text { No of } \\
\text { patients }\end{array}$ & $\begin{array}{l}\text { Sex } \\
(M / F)\end{array}$ & Age & $\begin{array}{l}\text { Weight } \\
\text { (kg) }\end{array}$ & $\begin{array}{l}\text { Dose } \\
(\mathrm{mg} / \mathrm{kg})\end{array}$ \\
\hline \multicolumn{6}{|l|}{ Neonates: } \\
\hline $\begin{array}{l}\text { Suppository } \\
\text { Nasogastric dose }\end{array}$ & $\begin{array}{l}9 \\
3\end{array}$ & $\begin{array}{l}6 / 3 \\
2 / 1\end{array}$ & $\begin{array}{l}11 \cdot 8(6.9 \text { to } 16 \cdot 7) \text { days } \\
12 \cdot 3(7 \cdot 3 \text { to } 17 \cdot 3) \text { days }\end{array}$ & $\begin{array}{l}3.7(3 \cdot 1 \text { to } 4 \cdot 3) \\
3 \cdot 3(2 \cdot 6 \text { to } 4 \cdot 0)\end{array}$ & $\begin{array}{l}18 \cdot 1(15 \cdot 2 \text { to } 21 \cdot 0) \\
15 \cdot 9(14 \cdot 4 \text { to } 17 \cdot 4)\end{array}$ \\
\hline $\begin{array}{l}\text { Infants: } \\
\text { Suppository }\end{array}$ & 10 & & & & \\
\hline $\begin{array}{l}\text { Suppository } \\
\text { Nasogastric dose } \\
\text { Children: }\end{array}$ & $\begin{array}{r}10 \\
5\end{array}$ & $\begin{array}{l}6 / 4 \\
3 / 2\end{array}$ & $\begin{array}{l}3.6(2.3 \text { to } 4.9) \text { months } \\
4.2(2.4 \text { to } 6.0) \text { months }\end{array}$ & $\begin{array}{l}4 \cdot 2(3.0 \text { to } 5 \cdot 4) \\
4 \cdot 3(2.6 \text { to } 6 \cdot 0)\end{array}$ & $\begin{array}{l}17 \cdot 9(14 \cdot 6 \text { to } 21 \cdot 2) \\
19 \cdot 6(17 \cdot 2 \text { to } 22 \cdot 0)\end{array}$ \\
\hline $\begin{array}{l}\text { Suppository } \\
\text { Nasogastric dose }\end{array}$ & $\begin{array}{l}9 \\
5\end{array}$ & $\begin{array}{l}5 / 4 \\
3 / 2\end{array}$ & $\begin{array}{l}2.7(0.8 \text { to } 4.6) \text { years } \\
2.3(0.9 \text { to } 3.7) \text { years }\end{array}$ & $\begin{array}{l}12 \cdot 4(9 \cdot 1 \text { to } 15 \cdot 7) \\
10 \cdot 9(8 \cdot 2 \text { to } 13 \cdot 6)\end{array}$ & $\begin{array}{l}15.3(13.0 \text { to } 17.6) \\
14.5(13.9 \text { to } 15.1)\end{array}$ \\
\hline
\end{tabular}



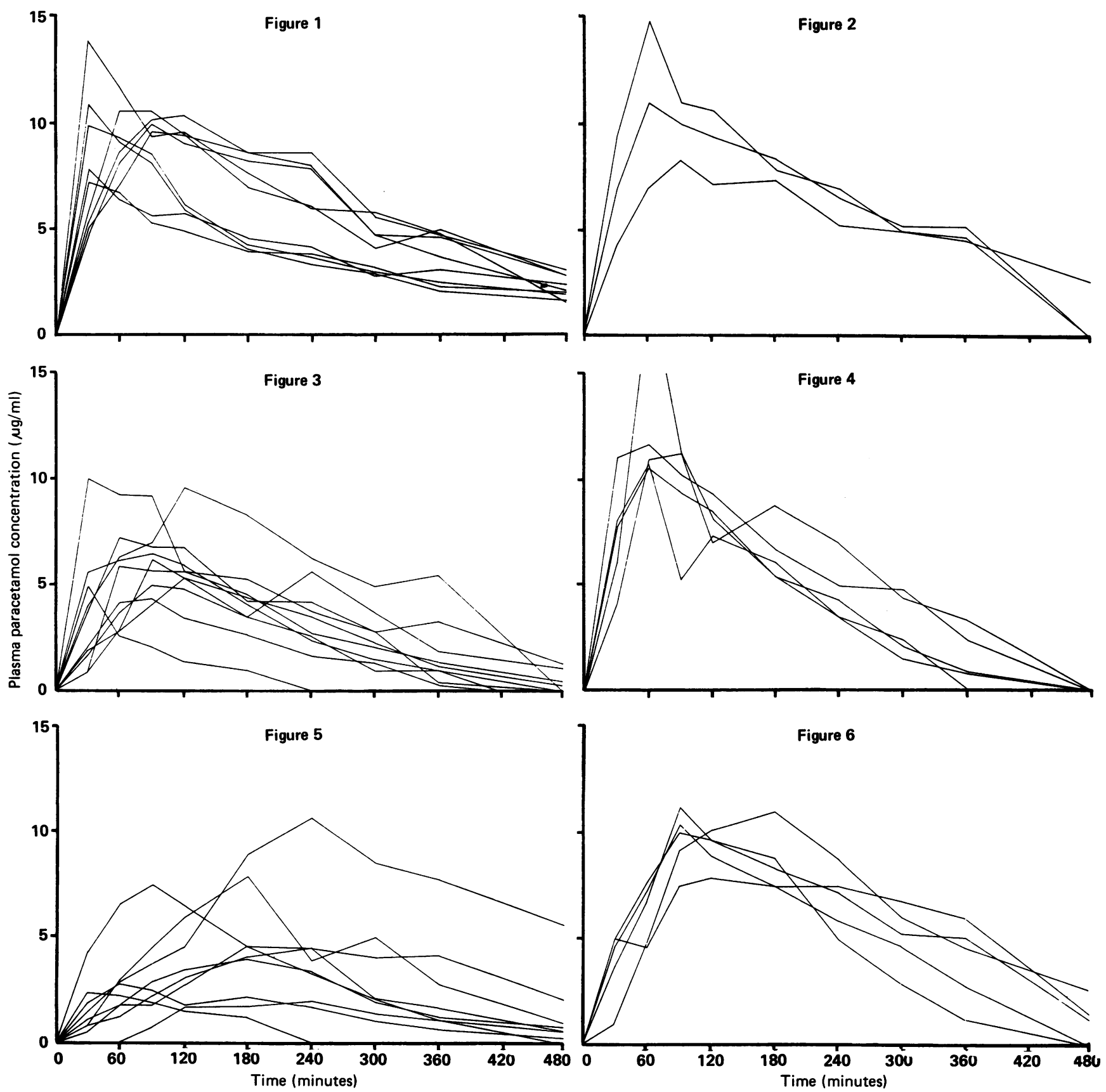

Figure 1 Plasma paracetamol concentration in neonates after suppository. Figure 2 Plasma paracetamol concentration in neonates after nasogastric dose.

Figure 3 Plasma paracetamol concentration in infants after suppository.

Figure 4 Plasma paracetamol concentration in infants after nasogastric dose.

Figure 5 Plasma paracetamol concentration in children after suppository.

Figure 6 Plasma paracetamol concentration in children after nasogastric dose.

Table 2 Area under curve (AUC), peak plasma concentration (Cmax), time to Cmax (Tmax), and elimination half life $\left(t^{1 / 2} \beta\right)$ results for all groups. AUC and Cmax normalised to a dose of $15 \mathrm{mg} / \mathrm{kg}$. Figures are mean ( $95 \%$ confidence interval)

\begin{tabular}{|c|c|c|c|c|}
\hline & $\begin{array}{l}\text { AUC } \\
(\mu g \cdot h o u r / m l)\end{array}$ & $\underset{(\mu g / m l)}{C \max }$ & $\begin{array}{l}\text { Time to } C \max \\
(\min )\end{array}$ & $\begin{array}{l}t^{t / 2 \beta} \boldsymbol{\beta} \\
\text { (hours) }\end{array}$ \\
\hline $\begin{array}{l}\text { Neonates: } \\
\text { Suppository } \\
\text { Nasogastric dose }\end{array}$ & $\begin{array}{l}46 \cdot 3(37 \cdot 4 \text { to } 55 \cdot 2) \\
58 \cdot 9(46 \cdot 0 \text { to } 71 \cdot 8)\end{array}$ & $\begin{array}{r}7 \cdot 9(7 \cdot 0 \text { to } 8 \cdot 8) \\
11 \cdot 2(9 \cdot 0 \text { to } 13 \cdot 4)\end{array}$ & $\begin{array}{l}58(22 \text { to } 94) \\
70 \text { (53 to } 87)\end{array}$ & $\begin{array}{l}3.8(2.7 \text { to } 4.9) \\
2.8(1.2 \text { to } 4.4)\end{array}$ \\
\hline $\begin{array}{l}\text { Infants: } \\
\text { Suppository } \\
\text { Nasogastric dose } \\
\text { Children. }\end{array}$ & $\begin{array}{l}21.9(12.8 \text { to } 31.0) \\
30.9(21.5 \text { to } 40.3)\end{array}$ & $\begin{array}{l}5 \cdot 7(3 \cdot 3 \text { to } 8 \cdot 1) \\
9 \cdot 7(6 \cdot 6 \text { to } 12 \cdot 8)\end{array}$ & $\begin{array}{l}78 \text { (46 to } 110) \\
66 \text { (53 to } 79)\end{array}$ & $\begin{array}{l}1.7(1.0 \text { to } 2.4) \\
1.6(0.8 \text { to } 2.4)\end{array}$ \\
\hline $\begin{array}{l}\text { Children: } \\
\text { Suppository } \\
\text { Nasogastric dose }\end{array}$ & $\begin{array}{l}26 \cdot 1(8 \cdot 0 \text { to } 44 \cdot 2) \\
56 \cdot 0(42 \cdot 1 \text { to } 69 \cdot 9)\end{array}$ & $\begin{array}{r}5 \cdot 3(2.0 \text { to } 8 \cdot 6) \\
10.5(9.0 \text { to } 12 \cdot 0)\end{array}$ & $\begin{array}{l}153(77 \text { to } 229) \\
114(75 \text { to } 153)\end{array}$ & $\begin{array}{l}2.6(1.4 \text { to } 3.8) \\
2.3(1.8 \text { to } 2.8)\end{array}$ \\
\hline
\end{tabular}




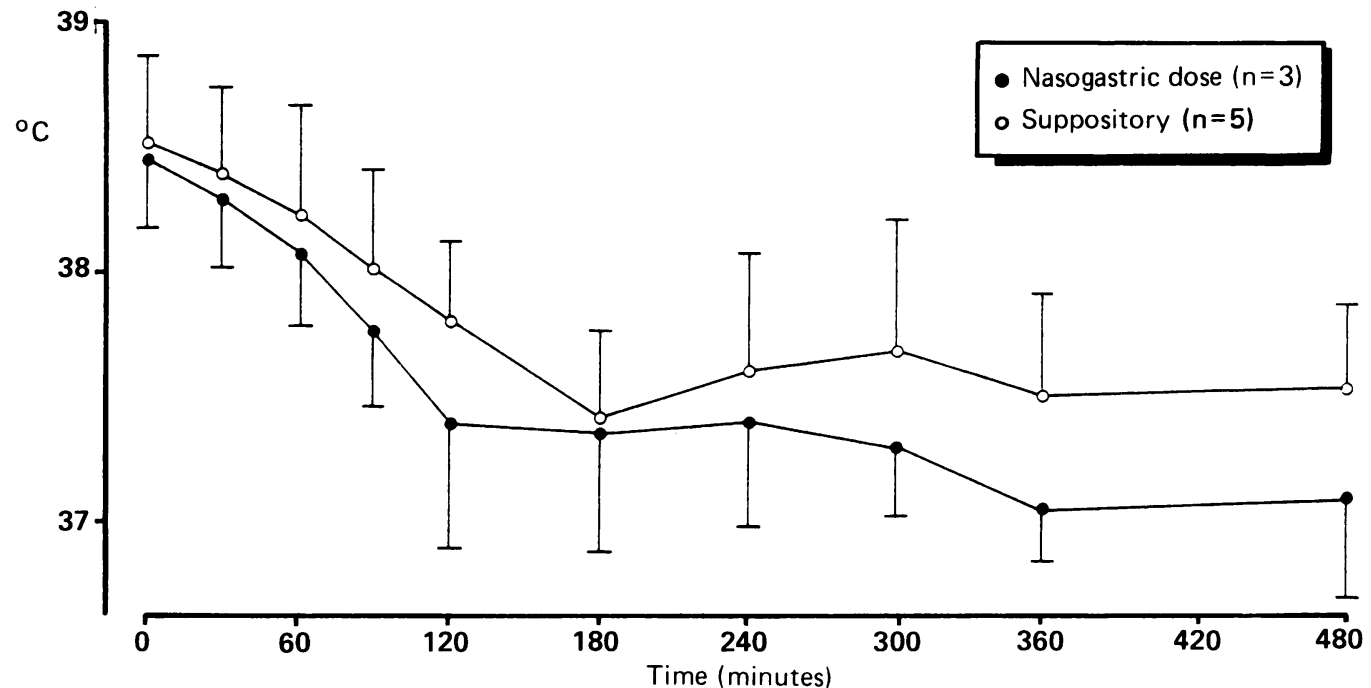

Figure 7 Mean temperature change in neonates after suppository or nasogastric dose (bar is $95 \%$ confidence interval).

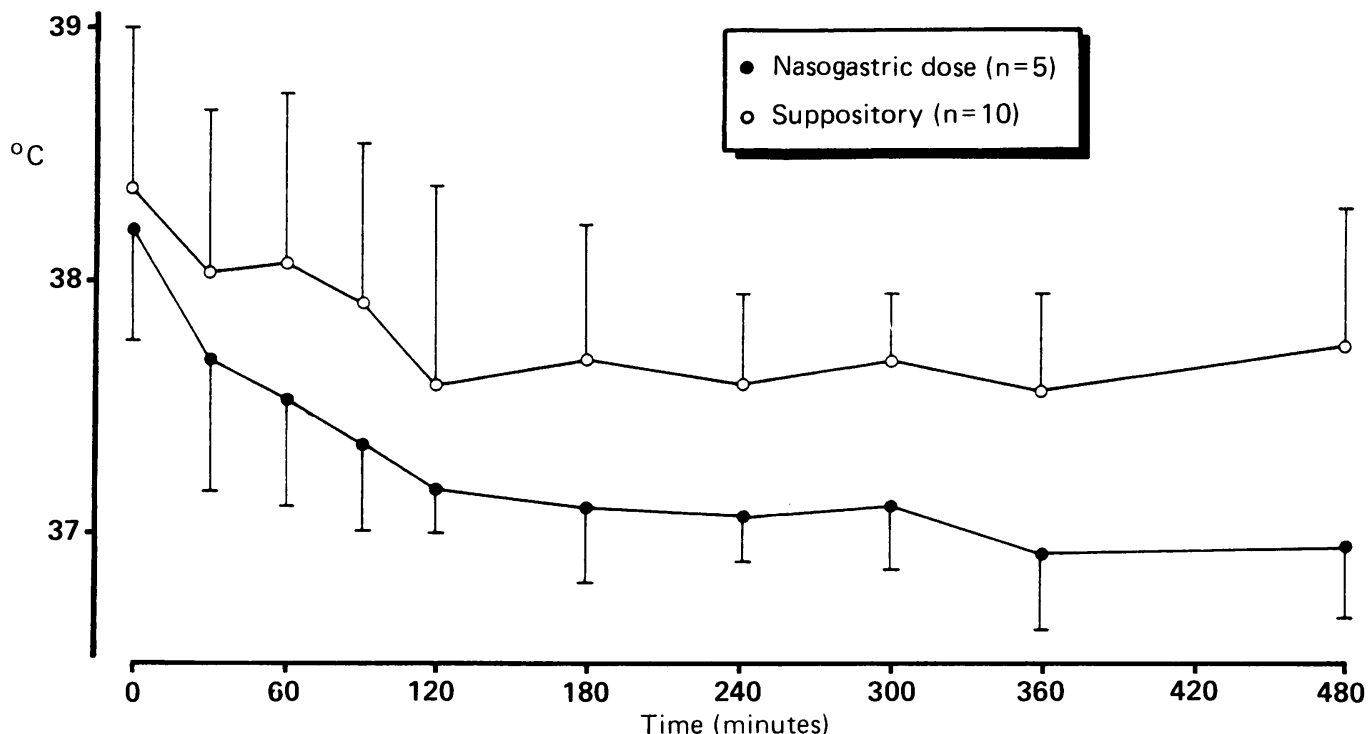

Figure 8 Mean temperature change in infants after suppository or nasogastric dose (bar is $95 \%$ confidence interval).

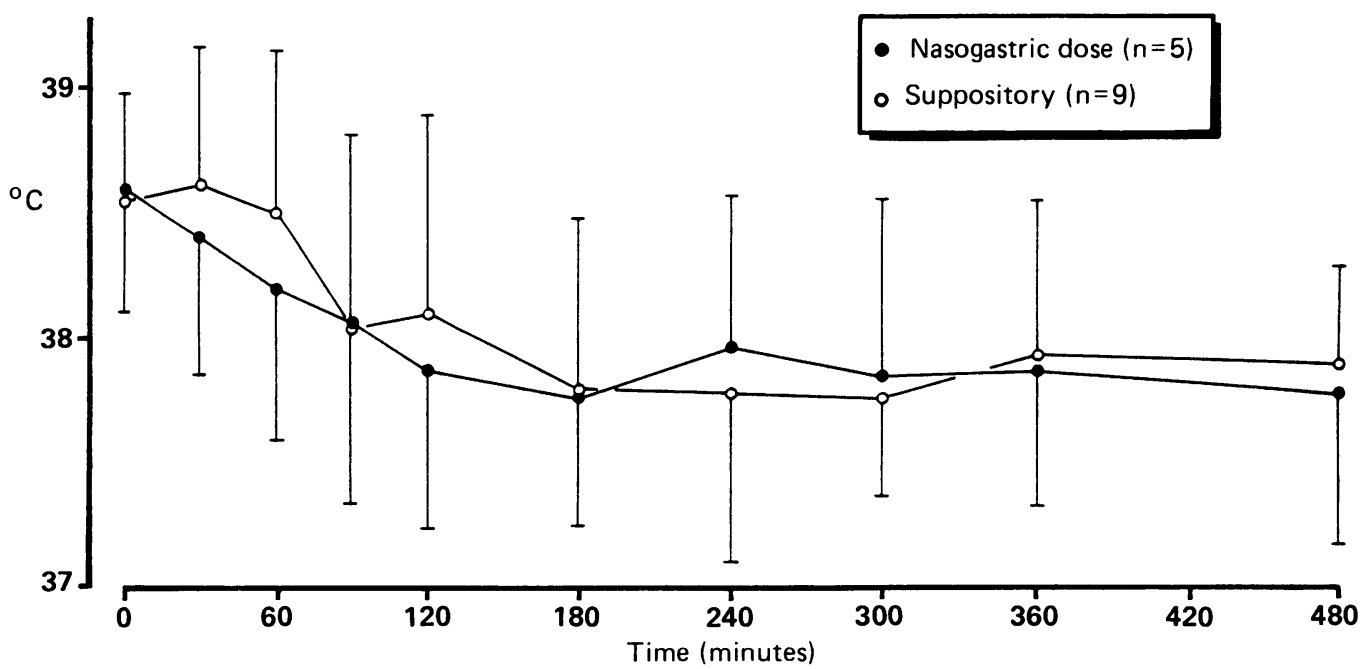

Figure 9 Mean temperature change in children after suppository or nasogastric dose (bar is $95 \%$ confidence interval). 
routes in neonates and infants. The mean AUC value in children after suppository was significantly lower than after nasogastric dosing (Kruskal-Wallis test $\mathbf{H}=6 \cdot 76, \mathrm{df}=1, \mathrm{p}=0.009$ ). The AUC in neonates after suppository was significantly greater than in infants or children ( $F$ ratio 9.8, $p=0.00099$ ). The AUC in children after nasogastric dosing was significantly lower than in neonates and children ( $F$ ratio $7 \cdot 24$, $\mathrm{p}=0.011)$. For AUC results after suppository combining all groups there was a significant correlation with dose thus:

AUC $(\mu \mathrm{g} / \mathrm{hour} / \mathrm{ml})=-33.8+3.9 \times$ dose $(\mathrm{mg} / \mathrm{kg}) \mathrm{r}=0.58, \mathrm{p}=0.003$

Cmax values were significantly lower after suppository compared with nasogastric dosing in neonates $(\mathrm{H}=5.72, \mathrm{df}=1, \mathrm{p}=0.016)$ and children $(\mathrm{H}=4 \cdot 27, \mathrm{df}=1, \mathrm{p}=0.037)$. There was no significant difference in $\mathrm{Cmax}$ values between age groups.

There was no significant difference within groups for time to maximum plasma concentration Tmax and for $t^{1 / 2} \beta$. The time to maximum plasma concentration was significantly prolonged in children after both suppository $(\mathrm{F}=8.73, \mathrm{p}=0.0016)$ and nasogastric dosing $(F=4.49, p=0.039)$. The $t^{1 / 2} \beta$ was significantly prolonged in neonates after suppository dosing $(F=9.75, p=0.001)$ but there was no significant difference between age groups after nasogastric dosing.

Figures 7 to 9 show mean changes in temperature for the three groups. Summary statistics of maximum individual fall in temperature were obtained and there was no significant correlation between Cmax, dose, AUC, and maximum temperature fall. Temperature reduction occurred in all groups with no significant differences within or between groups.

In all patients paracetamol concentrations were zero before commencing the study and results of liver function tests remained normal throughout.

\section{Discussion}

(1) SAFETY

Our results confirm the safety of single doses of paracetamol in this group of patients. Liver toxicity is likely if the plasma paracetamol concentration exceeds $120 \mu \mathrm{g} / \mathrm{ml}$ four hours after ingestion. ${ }^{15}$ In none of our patients did plasma paracetamol exceed $20 \mu \mathrm{g} / \mathrm{ml}$ at any time after doses of up to $25 \mathrm{mg} / \mathrm{kg}$.

(2) LOW (SUBTHERAPEUTIC) CONCENTRATIONS The effective plasma concentration of paracetamol for analgesia and antipyresis is quoted as $10-20 \mu \mathrm{g} / \mathrm{ml}{ }^{15}$ In our patients nasogastric paracetamol on the second postoperative day proved to be a more predictable means of achieving these concentrations than equivalent rectal doses given on the first postoperative day. The peak plasma concentrations after paracetamol suppositories were higher than those of 4.0 (SD 1.6) $\mu \mathrm{g} / \mathrm{ml}$ previously described after a (lower) dose of $10 \mathrm{mg} / \mathrm{kg}$ by suppository in nine children aged 7-12 years. ${ }^{11}$ The peak plasma concentrations after nasogastric administration are similar to those in another study with peaks of $9 \cdot 96-19 \cdot 6 \mu \mathrm{g} / \mathrm{ml}$ after $12-14 \mathrm{mg} / \mathrm{kg}$ of paracetamol elixir. ${ }^{12}$ The delay in achieving peak plasma concentrations in the older children after nasogastric dosing could be due to delayed gastric emptying as more of these patients were receiving opiates, which are known to decrease the rate of absorption of paracetamol.

The mean falls in temperature which we found were considerably less than in two previous studies comparing the antipyretic effects of oral and rectal paracetamol in febrile children. ${ }^{12}$ Their patients showed a range of fall in temperature of between 1.63 and $1.89^{\circ} \mathrm{C}$ after doses of $15-20 \mathrm{mg} / \mathrm{kg}$ paracetamol given rectally or orally. It is possible that the fever that follows cardiac surgery is less amenable to paracetamol treatment than is fever due to infection. The overall finding that plasma concentrations resulting from administration of suppositories were below accepted therapeutic values and that the antipyretic effects were disappointing indicates the need to assess the effects of higher rectal doses upon body temperature. Alternatively, different formulations of paracetamol for rectal use may be associated with greater bioavailability. ${ }^{1}$

(3) PLASMA HALF LIFE (T1/2 $\beta$ ) (FIG 10)

Mean $t^{1 / 2} \beta$ in children in this study ( $2 \cdot 3$ hours) resembles closely that previously found in adults after oral and intravenous administration $(2.5$ hours $) .{ }^{5}$ Similarly, $\mathrm{t}^{1 / 2} \beta$ in neonates $(3.8$ hours) after suppository is close to that previously determined in another urinary excretion study ( 3.5 hours). ${ }^{7}$ The difference between $t^{1 / 2} \beta$ values for neonates, infants, and children after nasogastric dosing was not significant and this is in agreement with earlier work. ${ }^{8}$

(4) Plasma CONCENTRATION TIME CURVE (AUC) (FIG 11)

The AUC is dependant upon both bioavailability and drug clearance. The relative bioavailability of oral and rectal paracetamol is known to be $<1.0$ therefore direct calculation of volume of distribution and clearance from the AUC is invalid. It has also been shown that the bioavailability of paracetamol is dose dependant,

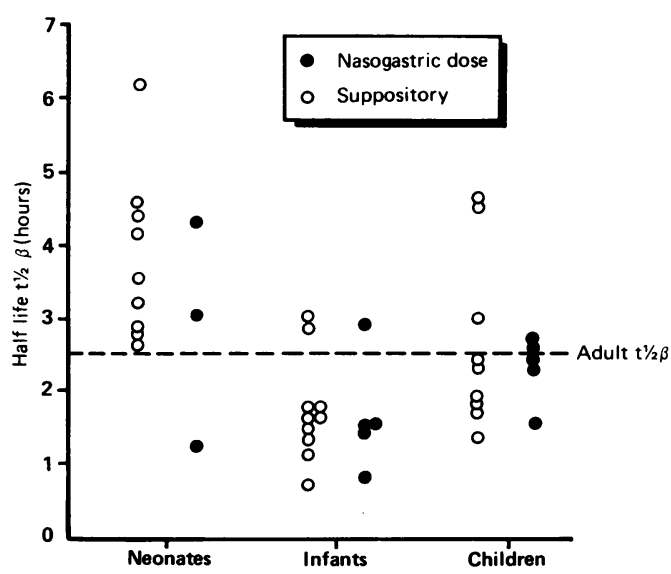

Figure 10 Individual elimination half life $\left(t^{1 / 2} \beta\right)$ for.all groups. 


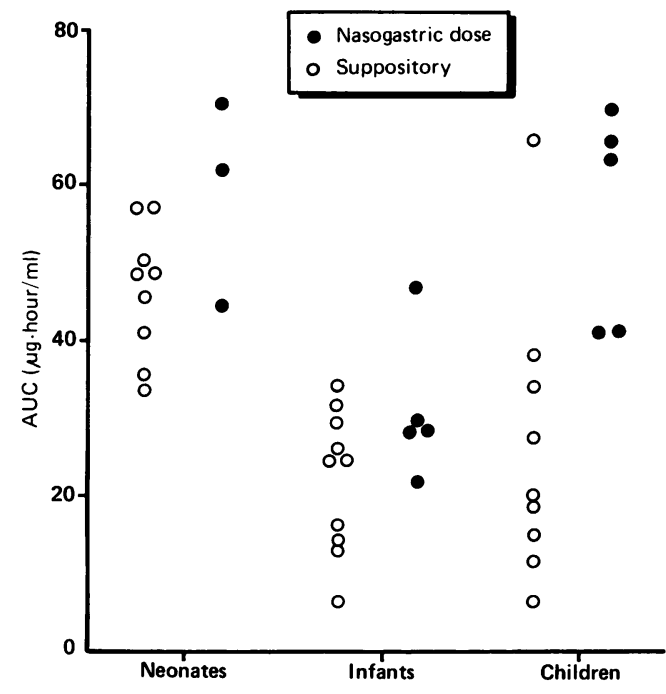

Figure 11 Individual area under curve (AUC) values for all groups.

and has greater variability at higher doses. The design of this study does not preclude an order effect as the suppositories were always administered before the nasogastric dose. There is no evidence from previous pharmacokinetic studies, however, to suggest that this would influence the results we obtained, and this is the sequence that is employed in clinical practice.

In summary, caution should always be employed when translating the results of pharmacokinetic studies to the clinical situation. We believe that the low absolute paracetamol concentrations may explain the disappointing clinical effect in our patients, although it is also possible that the fever which follows cardiac surgery is less amenable to paracetamol treatment than is fever due to infection.

It is apparent from this study that triglyceride based suppositories in a dose of $15 \mathrm{mg} / \mathrm{kg}$ may produce plasma concentrations that are subtherapeutic, but also nasogastric administration in children who have received opiates may be no more effective. The pharmacokinetic values are in agreement with previous findings. We believe that further studies are needed to see whether there is any tendency for paracetamol to accumulate in neonates after regular dosing with suppository in view of the prolonged half life, and to assess the response to increased dosing with suppository in older children. In the meantime, as one method of urgently reducing a child's temperature shortly after major surgery, if the oral route is not available, we would recommend a single triglyceride based suppository in a dose of $20-25 \mathrm{mg} / \mathrm{kg}$ as being safe and possibly more effective than previously recommended doses.

We wish to thank Andrew Johnson, MLSO at Myrtle Street We wish to thank Andrew Johnson, MLSO at Myrte Street concentrations and Abbott Diagnostics for supplying the TDx Paracetamol assay reagents.

1 Keinanen S, Hietula M, Simila S, Kouvalalainen K. Antipyretic therapy: a comparison of rectal and oral paracetamol Eur f Clin Pharmacol 1977;12:77-80.

2 Vernon S, Bacon C, Weightman D. Rectal paracetamol in small children with fever. Arch Dis Child 1979;54:469-71. Booker PD. Analgesia in children [Editorial]. Anaesthesia 1987;42:343-4.

4 Kirklin JW, Barratt-Boyes BG. Cardiac surgery. Edinburgh Churchill Livingstone, 1986.

5 Rawlins MD, Henderson DB, Hijab AR. Pharmacokinetics of paracetamol after intravenous and oral administration. Eur Clin Pharmacol 1977;11:283-6.

6 Seideman P, Alvan G, Andrews RS, Larross A. Relative bioavailability of a paracetamol suppository. Eur f Clin Pharmacol 1980;17:465-8.

7 Levy G, Khanna NN, Soda DM, Tsuzuki O, Stern L. Pharmacokinetics of acetaminophen in the human neonate: formation of acetaminophen glucuronide and sulphate in neonates in relation to plasma bilirubin concentration and neonates in relation to plasma bilirubin concentration and
D-glucuronic acid excretion. Pediatrics 1975;55:818-25.

8 Miller RP, Roberts RJ, Fischer LJ. Acetaminophen elimin ation kinetics in neonates, children and adults. Clin ation kinetics in neonates,
Pharmacol Ther 1976;19:284-94.

9 Lederman S, Fysh WJ, Tredger M, Gamsu HR. Neonatal paracetamol poisoning: treatment by exchange transfusion. Arch Dis Child 1983;58:631-3.

10 Roberts I, Robinson MJ, Mughal MZ, Ratcliffe JG, Prescott LF. Paracetamol metabolites in the neonate following maternal overdose. Br $\mathcal{F}$ Clin Pharmacol 1984;18:201-6.

11 Keinanen-Kiukaanniemi S, Simila S, Luoma P, Kangas L, Saukkonen A-L. Antipyretic effect of plasma concentrations of rectal acetaminophen and diazepam in children. Epilepsia 1979;20:607-12.

12 Nahata MC, Powell DA, Durrell DE, Miller MA. Acetaminophen accumulation in paediatric patients after repeated therapeutic doses. Eur $\mathcal{F}$ Clin Pharmacol 1984;27: 57-9.

13 Warner A. Drug use in the neonate: interrelationship of pharmacokinetics, toxicity and biochemical maturity. Clin

14 Greene JW, Craft L, Ghishan F. Acetaminophen poisoning in infancy. Am $\mathcal{J}$ Dis Child 1983;137:386-7.

15 Rumack BH. Aspirin versus acetaminophen: a comparative view. Pediatrics 1978;62:943-6. 